\title{
Regulation of adenylate cyclase activity and stimulation response in relation to endometrial receptivity in the rabbit
}

\author{
M. A. Fortier, A. P. Boulet and R. D. Lambert \\ Ontogénie et Reproduction, Centre de Recherches du Centre Hospitalier de l'Université Laval, \\ Ste-Foy, Quebec, Canada G1V $4 G 2$
}

\begin{abstract}
Summary. Adenylate cyclase activity was measured in broken cell preparations of whole endometrial tissue from rabbits on Days $0,1,6 \cdot 5,9$ and 15 of pseudopregnancy and in endometrial epithelial and stromal cells on Days 1 and 6.5 to assess the specific response of individual cell types. In dispersed cells, adenylate cyclase activity was higher $(P<0.01)$ in stromal than in epithelial cells and reduced on Day 6.5 compared to Day 1 in both cell types. The response of adenylate cyclase to isoproterenol appeared more important relative to the PGE-2 response in epithelial than in stromal cells and strongly reduced in the former on Day 6.5. In endometrium, the overall adenylate cyclase activity was increased significantly on Day 1 of pseudopregnancy compared to Day 0 (oestrus), only $18 \mathrm{~h}$ after injection of hCG. On the following days, the activity decreased progressively on Days 6.5 and 9 and exhibited a recovery on Day 15 . Adenylate cyclase response to isoproterenol (\% over GTP) was comparable on Days 0 , 1 and $6 \cdot 5$, abolished on Day 9 and recovered on Day 15 . Maximal response to PGE-2 (\% over GTP) was observed on Day 6.5, at the time of implantation, maintained on Day 9 and reduced on Day 15 towards the low levels measured in oestrus and Day 1 of pseudopregnancy. Our results demonstrate a dramatic alteration of adenylate cyclase activity in rabbit endometrium during pseudopregnancy. It suggests a possible involvement of catecholamines and prostaglandin E-2 in the regulation of endometrial receptivity through a cAMP-mediated process.
\end{abstract}

Keywords: endometrium; prostaglandins; cyclic AMP; catecholamines; decidual reaction

\section{Introduction}

The time at which the early embryo can elicit endometrial transformations to initiate implantation has been termed uterine receptivity (Psychoyos, 1986). The receptive period is controlled by ovarian sex steroids, develops shortly before implantation and is maintained for a limited time (Psychoyos, 1986). The earliest event associated with implantation is an increase in vascular permeability, common to all placental mammals (Psychoyos \& Casimiri, 1980), followed by the decidual cell reaction in rodents (Kennedy, 1986) and primates including man (Hearn, 1986). Prostaglandin (PG) E-2 appears to be the mediator that initiates these events but the precise mechanism by which it is effective is not fully determined (Kennedy, 1987). It is possible to induce the decidual cell reaction artificially with exogenous PGE-2 after priming with a definite sequence of oestradiol and progesterone (Johnston \& Kennedy, 1984). The source of PGE-2 for induction of the process in vivo may be the blastocyst itself or the endometrium in response to the presence of the embryo (Harper et al., 1983) or following alteration in steroid levels (Kuehl et al., 1976). In several systems, cAMP mediates the PGE-2 response and such a mechanism has been proposed for induction of the decidual reaction (Rankin et al., 1977). Indeed, cAMP levels are increased at sites of increased vascular permeability (Villar-Rojas et al., 1982) and agents such as cholera toxin which 
are known to increase cAMP levels are able to induce the decidual reaction (Kennedy, 1983). The stroma appears to be the target for PGE-2 action. In the rat, specific binding sites for PGE-2 were found in the stroma but not in the luminal epithelium (Kennedy et al., 1983). Similarly, in rabbit endometrium, we have found that adenylate cyclase activity was stimulated by PGE-2 to a greater extent in cultured stromal cells than in epithelial cells (Fortier et al., 1987). Furthermore, the PGE-2 response in cultured cells was increased after progesterone treatment compared to that after oestradiol, thus suggesting that it could be regulated by sex steroids in vivo and involved in the development of uterine receptivity. However, to date, conclusive evidence for a cAMP mediation of PGE-2 action in the decidual reaction is not available (Kennedy, 1986).

The cAMP generating system may also be involved in the response to the presence of the embryo. In the rat, a dense population of $\beta$-adrenergic receptors has been localized in the luminal epithelium by autoradiography (Tolszczuk et al., 1985) and we have shown that, in the rabbit, these receptors were tightly coupled to adenylate cyclase in epithelium of oviduct and uterus (Fortier \& Boulanger, 1986). These receptors mediate epithelial cell proliferation in the mammary gland (Yang et al., 1980) and PG synthesis in the rat uterus (Chaud et al., 1986).

In the present study, we have investigated the regulation of adenylate cyclase and its stimulation response at different stages of pseudopregnancy in rabbits. The aim of the study was to evaluate a possible role of the cAMP generating system in endometrial receptivity.

\section{Materials and Methods}

Animals and treatments. New Zealand White rabbits, weighing $3.5 \mathrm{~kg}$, at oestrus (purple and oedematous vulvae) were selected. Pseudopregnancy was induced by i.v. injection of $75 \mathrm{i}$.u. hCG (APL: Ayerst Laboratories, Montreal, Quebec, Canada) 18 h (Day 1) and 6.5, 9 and 15 days (Days 6.5,9 and 15) before collection of genital tracts. These days were chosen as the best representation of the different physiological states during pseudopregnancy in the rabbit. Oestrus appeared as a self imposed control. Day I was a second control in which hCG and ovulation reduced individual variations in the hormonal status. Day 6.5 is the time of implantation in the rabbit and should be a good representation of maximal uterine receptivity. Day 15 appears as the earliest time at which it is possible to induce an ovulation that yields viable embryos (Fischer et al., 1986). Day 9 was chosen arbitrarily between Days 6.5 and 15 as an intermediate point with high circulating concentrations of progesterone (Dugre et al., 1988). Animals were killed by cervical dislocation and the ovaries were examined for counts of the number of follicles or for signs of ovulation. Uterine horns were dissected out aseptically and placed in a Petri dish containing freshly gassed $\left(5 \% \mathrm{CO}_{2}-95 \% \mathrm{O}_{2}\right)$ incomplete Hanks' balanced salt solution (IHBSS, $\mathrm{Ca}^{2+}$ - and $\mathrm{Mg}^{2+}$-free, $\mathrm{pH} 7.5$ ) (Fortier et al., 1983).

Preparation of dispersed cells. Endometrial cells were prepared as described previously (Fortier et al., 1987). Briefly, uterine horns collected from animals on Days 1 and 6.5 of pseudopregnancy were everted and submitted to a first digestion with $0.375 \%$ trypsin (Type III: Sigma, St Louis, MO, USA) in IHBSS for $90 \mathrm{~min}$ at $4^{\circ} \mathrm{C}$ followed by $90 \mathrm{~min}$ at $25^{\circ} \mathrm{C}$ to yield epithelial cells. The tissue was then submitted to a second digestion with trypsin $(0.03 \%)$, collagenase (Type II; $0.03 \%$; Sigma) and DNase-I $\left(0.20 \%\right.$; Sigma), for $45 \mathrm{~min}$ at $37^{\circ} \mathrm{C}$ to recover stromal cells. The cells were then washed by centrifugation and the final pellet was either resuspended in cyclase homogenization buffer (CHB; $0.05 \mathrm{M}$-Hepes, $0.001 \mathrm{M}$-EGTA) and $10 \%(\mathrm{v} / \mathrm{v})$ dimethylsulphoxide, $\mathrm{pH} 7.6)$ at $4^{\circ} \mathrm{C}$ to determine adenylate cyclase activity or cultured in RPMI 1640 (Flow Lab, Mississauga, Ontario, Canada) supplemented with 10\% (v/v) fetal bovine serum to assess long-term viability and morphological identity.

Preparation of endometrial tissue. Uterine horns were collected from animals at oestrus (Day 0) and on Days 1, 6.5, 9 and 15 of pseudopregnancy. Fresh endometrial tissue was then obtained by scraping the uterine horns, opened longitudinally, with a microscope slide. The tissue was diluted in $10 \mathrm{ml} \mathrm{CHB}$ at $4^{\circ} \mathrm{C}$ and homogenized with a polytron tissue disintegrator (Brinkman PT-10) adjusted at 5 for $20 \mathrm{sec}$. The homogenate was filtered through a nylon mesh $\left(0.16 \mathrm{~mm}^{2}\right)$ and centrifuged at $30000 \mathrm{~g}$ for $20 \mathrm{~min}$ at $4^{\circ} \mathrm{C}$. The pellet was washed twice, resuspended in CHB to obtain a protein concentration between 1.0 and $1.5 \mathrm{mg} / \mathrm{ml}$ and used fresh.

Determination of adenylate cyclase activity in dispersed cells and fresh tissue. Adenylate cyclase (EC 4.6.1.1) activity was defined as the enzymic conversion of $\alpha-\left[{ }^{32} \mathrm{P}\right] \mathrm{ATP}$ to $\left[{ }^{32} \mathrm{P}\right] \mathrm{CAMP}$ in $5 \mathrm{~min}$ in a broken cell preparation from dispersed cells or fresh tissue. The method has been used previously for enodmetrial cells and tissue (Fortier et al., 1987) and described in detail elsewhere (Krall \& Korenman, 1979; Krall et al., 1981). The enzyme activity was determined in its basal state (no addition) and after stimulation with fluoride (NaF, $0.02 \mathrm{M})$ guanosine triphosphate (GTP, 25 $\mu \mathrm{M}$ ) and increasing doses of isoproterenol and PGE-2 from $1 \mathrm{nM}$ to $100 \mu \mathrm{M}$ in the presence of GTP $(25 \mu \mathrm{M})$ and using $\mathrm{Mg}^{2+}(20 \mathrm{~mm})-\mathrm{ATP}$ as a substrate.

The protein content was determined by the folin-phenol reaction (Lowry et al., 1951). 
Data calculation and statistical analysis. Maximal response and half-maximal stimulation were calculated from dose response curves using a weighted iterative non-linear least-square regression (Rodbard, 1974). Statistical comparisons were done by the Duncan-Kramer multiple-range test and by two-way analysis of variance.

\section{Results}

The long-term viability and purity of epithelial and stromal cells was assessed by in-vitro culture for 7 days. The growth and morphological properties of endometrial cells isolated from Day-1 pseudopregnant animals were identical to those already reported (Fortier et al., 1987).

Cells from Day-7 animals exhibited a lower yield and viability decreased from $95 \%$ at the end of preparation to $50 \% 24 \mathrm{~h}$ after plating. However, the morphological properties of these cells were comparable to those of Day 1.

Adenylate cyclase activity was higher $(P<0.01)$ in stromal than in epithelial cells on Days 1 and 6.5 (Figs 1a, b). For both cell types, the activity was higher $(P<0.05)$ on Day 1 than on

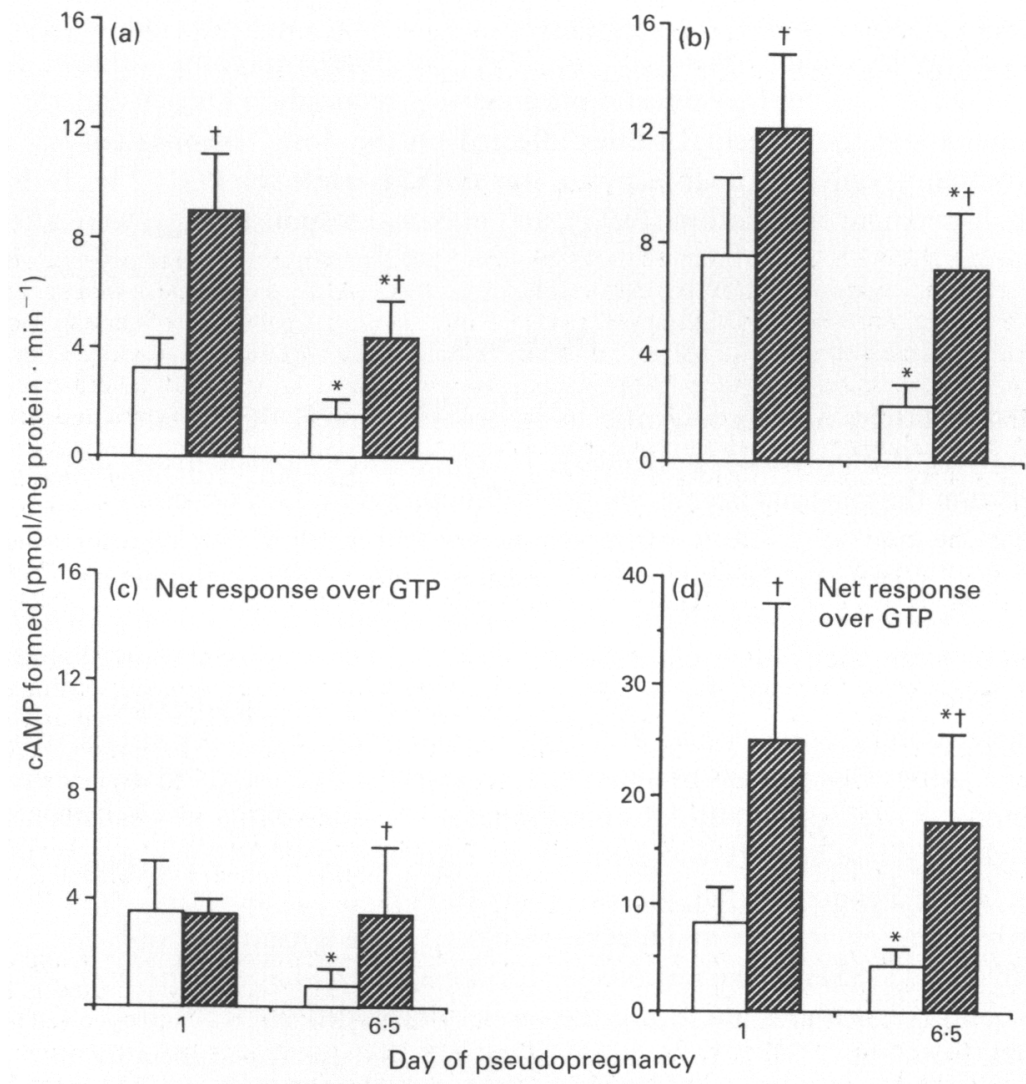

Fig. 1. Comparison of adenylate cyclase activity on Days 1 and 6.5 of pseudopregnancy in epithelial ( $\square$ ) and stromal ( cells freshly isolated from rabbit endometrium. Adenylate cyclase was determined in a broken cell preparation by conversion of $\alpha-\left[{ }^{32}\right.$ P]ATP to $\left[{ }^{32} \mathrm{P}\right] \mathrm{cAMP}$ in $5 \mathrm{~min}$ in the presence of (a) $\mathrm{Mg}^{2+}(20 \mathrm{mM}$, basal), (b) GTP $(25 \mathrm{mM})$, (c) GTP + isoproterenol $(10 \mu \mathrm{M})$, and (d) GTP + PGE-2 $(10 \mu \mathrm{M})$. The results obtained from 4 different cell preparations are mean \pm s.e. of triplicate measurements. Adenylate cyclase response (c) and (d) was defined as total activity (GTP + isoproterenol or GTP + PGE-2) less activity measured in the presence of GTP alone (b). ${ }^{*} P<0.01$ compared with value for that cell type on Day $1 ; \dagger P<0.01$ compared with value for epithelial cells on that day. 
Day 6.5. Adenylate cyclase activity was stimulated by isoproterenol and PGE-2 in the two cell types (Figs Ic, d). The PGE-2 response was higher in stromal than in epithelial $(P<0.05)$ cells and reduced in the latter on Day 6.5 compared to Day 1 of pseudopregnancy (Fig. 1d). The response to isoproterenol was comparable in epithelial and stromal cells on Day 1 and reduced $(P<0 \cdot 01)$ on Day 6.5 only in the epithelial cells (Fig. 1c).

Adenylate cyclase activity and stimulation response were measured in whole endometrium during oestrus and pseudopregnancy. The enzyme activity was greatly affected by the hormonal status of the animals. The activity was altered similarly in basal conditions (Fig. 2a) and after stimulation with GTP (Fig. 2b) or NaF (not shown). The activity increased significantly $(P<0.05$ ) at Day $1,18 \mathrm{~h}$ after injection of hCG, compared to that on Day 0 . The activity levels then decreased progressively on Days 6.5 and 9, to below the values at Day 0, and finally increased on Day 15 . Adenylate cyclase response to isoproterenol and PGE-2 at $10 \mu \mathrm{M}$ were altered (Figs $2 \mathrm{c}$, d) and the dose-response curves (Fig. 3) also differed according to the physiological state. Absolute values (pmol cAMP formed/mg protein $\mathrm{min}^{-1}$ ) corresponding to the relative response illustrated in Fig. 3 at $10^{-5} \mathrm{M}$ are those reported in Fig. 2, $0 \%$ stimulation being the response in presence of GTP alone. The net isoproterenol response, expressed as a percentage of activity in the presence of GTP alone (Fig. 3a), reveals that the response was comparable on Days 0,1 and 6.5, but abolished on Day 9 and increased on Day 15 . On the other hand, the PGE-2 response was comparable on Days 0 and 1 , increased to its highest level on Day 6.5 and progressively reduced on Days 9 and 15.

Table 1 summarizes the principal values affected on the dose-response curves. It illustrates that, for isoproterenol, only maximal response was altered, while for PGE-2 both the sensitivity, estimated by half-maximal stimulation $\left(\mathrm{EC}_{50}\right)$, and maximal response $\left(\mathrm{V}_{\text {max }}\right)$ were affected.

\section{Discussion}

Adenylate cyclase activity and its response to isoproterenol and PGE-2 are strongly affected in rabbit endometrium during pseudopregnancy. In preparations issued from dispersed cells and whole endometrium the general enzyme activity is diminished on Day 6.5 compared to Day 1 . This diminution may be due to dilution by increased protein content during uterine hypertrophy (Arnold \& Shorey, 1986). In the particulate fraction from whole endometrium, the activity of adenylate cyclase was increased significantly on Day 1 compared to Day 0 only $18 \mathrm{~h}$ after injection of hCG. It suggests that adenylate cyclase is a primary target during regulation of protein turnover by sex steroids. Therefore, to eliminate the effect of protein content on adenylate cyclase activity, its response to stimulation by isoproterenol and PGE-2 was expressed as a percentage of activity in the presence of GTP alone. This process permits estimation of the fraction of adenylate cyclase activity coupled to stimulatory receptors but does not influence the estimation of sensitivity. On Day 6.5, although adenylate cyclase activity was reduced, its response to PGE-2 was maintained at a high level. In whole Day-6.5 endometrium, the sensitivity to PGE-2 was increased more than 1000-fold. At this time, which represents maximal uterine receptivity, the appearance of high affinity sites for PGE-2 (Asboth et al., 1985) may be responsible for the atypical shape of the dose-response curve. Although the computer programme using the model developed by Rodbard (1974) was able to accept the data from the PGE-2 response of Day 6.5, its use was probably not appropriate. However, from visual observation of dose-responses to PGE-2, mathematical or statistical treatment does not appear necessary to distinguish Day 6.5 as more responsive and sensitive to stimulation. The regulation of isoproterenol response was completely different from that of PGE-2. The $\beta$-adrenergic response was totally abolished on Day 9 and reached maximal levels on Day 15 just before return to oestrus (Fischer et al., 1986). Conversely, the PG response was maximal on Days 6.5 and 9 and then diminished progressively on Days 15 and 0.

Furthermore, only the magnitude of adenylate cyclase response was affected with isoproterenol while with PGE-2 the sensitivity of the enzyme and the maximal response were regulated. During 


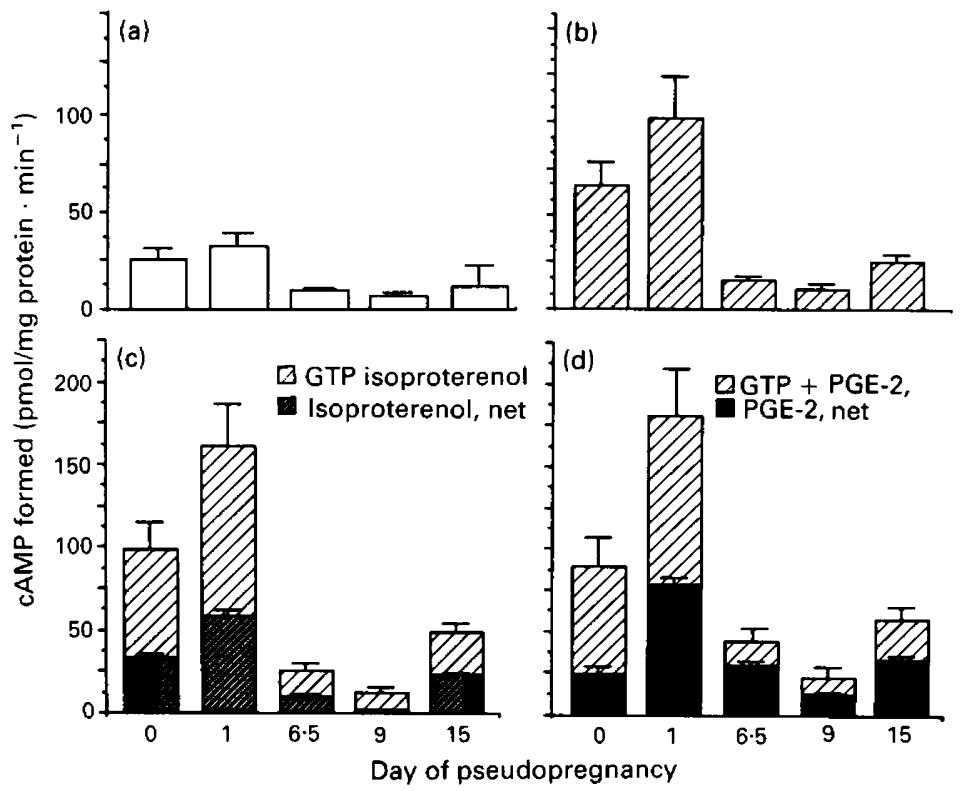

Fig. 2. Comparison of adenylate cyclase activity in fresh endometrial tissue collected from rabbits on Day 0 (oestrus) and Days 1, 6.5, 9 and 15 of pseudopregnancy. (a) Basal; (b) GTP $(25 \mu \mathrm{M})$; (c) GTP + isoproterenol $(10 \mu \mathrm{M})$; (d) GTP + PGE-2 $(10 \mu \mathrm{M})$. In (c) and (d) the whole bar represents total activity and the lower part represents the agonist sensitive response. The results are mean \pm s.e. for: 3 (Day 1), 4 (Days 9 and 6.5) or 5 (Days 9 and 15) experiments run in triplicate. In each panel, values on Day 1 were higher $(P<0.01)$ and on Day 9 were lower $(P<0.01)$ than those on all other days.

(a) Isoproterenol

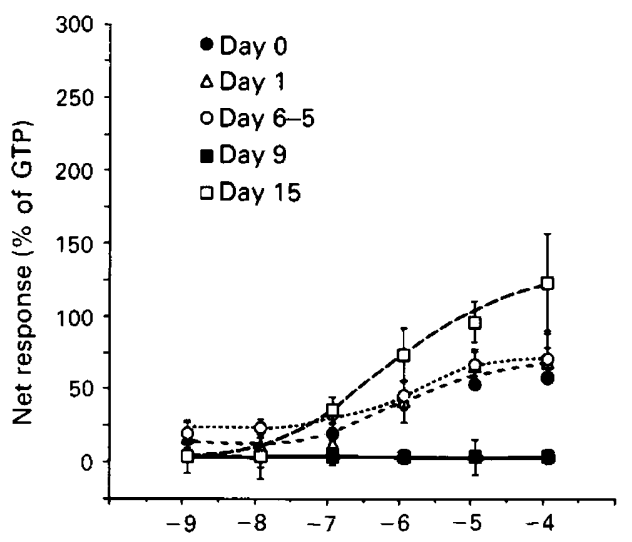

(b) PGE-2

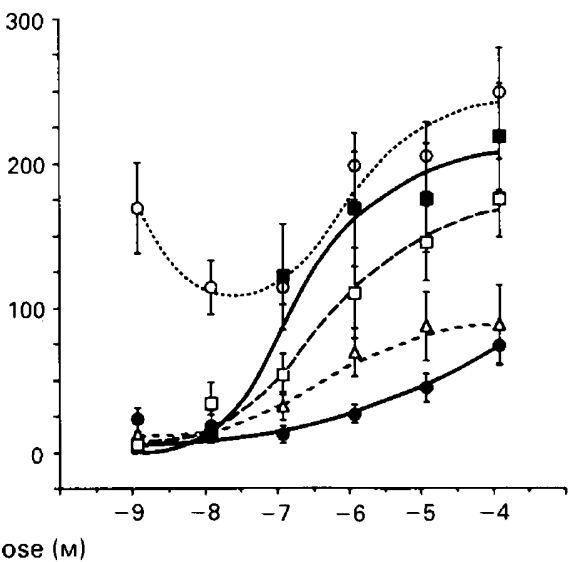

Fig. 3. Influence of pseudopregnancy on adenylate cyclase response to increasing concentrations of (a) isoproterenol and (b) PGE-2 in fresh endometrium measured in the presence of GTP $(25 \mu \mathrm{M}$ ). The results represent the mean \pm s.e. of 3 (Day 1), 4 (Days 0 and 6.5) or 5 (Days 9 and 15) experiments run in triplicate. 
Table 1. Activation values of adenylate cyclase calculated $\ddagger$ from dose-responses to isoproterenol and PGE-2

\begin{tabular}{lccccc}
\hline & \multicolumn{2}{c}{ Isoproterenol response } & & \multicolumn{2}{c}{ PGE-2 response } \\
\cline { 2 - 3 } \cline { 5 - 6 } Group & $\begin{array}{c}\mathrm{EC}_{50}{ }^{*} \\
(\mu \mathrm{M})\end{array}$ & $\begin{array}{c}\mathrm{V}_{\max } \dagger^{\dagger} \\
(\% \text { over GTP })\end{array}$ & $\begin{array}{c}\mathrm{EC}_{50}{ }^{*} \\
(\mu \mathrm{M})\end{array}$ & $\begin{array}{c}\mathrm{V}_{\max }{ }^{\dagger} \\
(\% \text { over GTP })\end{array}$ \\
\hline Day 0 & 0.89 & 52 & & 17 & 84 \\
Day 1 & 0.95 & 63 & & 0.35 & 86 \\
Day 6.5 & 0.91 & 72 & & 0.001 & 200 \\
Day 9 & $\mathrm{N} . \mathrm{D}$. & 0 & & 0.066 & 192 \\
Day 15 & 0.67 & 129 & & 0.67 & 203 \\
\hline
\end{tabular}

*Concentration of agonist at which half-maximal stimulation was obtained.

† Maximal stimulation level calculated from dose-response curves.

$\mp \mathrm{V}_{\max }$ and $\mathrm{EC}_{50}$ were calculated by the model of Rodbard (1974) using a weighted iterative non-linear least-square regression.

pseudopregnancy, the increased progesterone concentrations appear to favour PGE-2 response while decreasing values, jointly with a rise in tissue oestradiol on Day 15 (unpublished data) favour the isoproterenol response. The difference in regulation of the isoproterenol and PGE-2 response may result from unequal distribution between endometrial cell types. Indeed, the results obtained with dispersed cells from rabbit (Fortier \& Boulanger, 1986) and cow (Fortier et al., 1988) endometrium, showed that the PGE-2 response resides primarily in the stromal cells while the isoproterenol response predominates in epithelial cells. In epithelium, a $\beta$-adrenergic response has been associated with epithelial cell growth in the mammary gland (Yang et al., 1980) and with PG synthesis in the uterus (Arnold \& Shorey, 1986; Fortier et al., 1988). These cells which are in close contact with the blastocyst may therefore use this system to relay or amplify the embryonic signal (Wilmut et al., 1986) towards the stroma. Specific functions for the different cell types of endometrium during embryo-maternal interactions have indeed been proposed (Moulton \& Koenig, 1986).

The regulation of the PGE-2 response observed in the particulate fractions of endometrium during pseudopregnancy appears closely related to that in stromal cells cultured in the presence of progesterone (Fortier et al., 1987). This is not surprising since the stroma constitutes the major portion of the endometrium. The regulation of hormonal response by sex steroids in vivo probably depends on the oestradiol to progesterone ratio rather than on the presence of one or the other (Bolander, 1984). In myometrial cell cultures, we have shown that this ratio was critical for the regulation of $\beta$-adrenegic response (Boulet \& Fortier, 1988). To date, although circumstantial evidence suggests that cAMP is involved in the decidual cell reaction, no definite data have demonstrated its involvement in the mediation of PGE-2 action on endometrium. Other mediation mechanisms such as phospholipid breakdown have been proposed but the results with the rat have demonstrated an inhibitory effect of protein kinase $\mathrm{C}$ activators on the decidual reaction (Feyles \& Kennedy, 1987).

In a previous study, we have shown that adenylate cyclase was highly responsive to PGE-2 in cultured stromal cells and that it could be regulated by sex steroids (Fortier et al., 1987). In the present study, we demonstrate that, during pseudopregnancy, the sensitivity and response to PGE-2 are regulated in a way that mimics uterine receptivity. In addition, the isoproterenol response primarily located on epithelial cells was also regulated but differently from the PGE-2 response. Our results demonstrate that the adenylate cyclase system of rabbit endometrium is a primary target for modulation by the hormonal status and that its response to PGE-2 may determine uterine receptivity. 
This work was supported by grants from the Natural Sciences and Engineering Research Council of Canada (NSERC), No. U0389 (M.A.F.) and No. A2788 (R.D.L.). M.A.F. is holder of a fellowship from NSERC and 'Le Fonds de la Recherche en Santé du Québec' (FRSQ). A.B. is holder of a studentship from FRSQ. We thank Mrs Josée Poulin for the preparation of this manuscript.

\section{References}

Arnold, R. \& Shorey, C.D. (1986) Morphology and morphometry of the rabbit uterus during pseudopregnancy. Acta anat. 127, 119-124.

Asboth, G., Tood, H., Toth, M. \& Hertelendy, F. (1985) $\mathrm{PGE}_{2}$ binding synthesis and distribution in hen oviduct. Am. J. Physiol. 11, E80-88.

Bolander, F.F. (1984) Enhanced endocrine sensitivity of mouse mammary glands: hormonal requirements for induction and maintenance. Endocrinology 115, 630633

Boulet, A.P. \& Fortier, M.A. (1988) Sex steroid regulation of $\beta$-adrenergic sensitive adenylate cyclase in rabbit myometrial cells in primary culture. Life $S c i$. 42, 829-840.

Chaud, M.A., Franchi, A.M., Gonzales, E.T., Gimeno, M.F. \& Gimeno, A.L. (1986) Norepinephrine alters $\mathrm{PGE}_{2} / \mathrm{PGE}_{1}$, output ratio in isolated uterus from ovariectomized rats. Prostagl. Leukotr. Med. 22 , 201-210.

Dugré, F.J., Lambert, R.D., Boulanger, A. \& Fortier, M.A. (1988) Relationship between steroid levels in peripheral serum and uterine tissue during pseudopregnancy in the rabbit. Theriogenology (in press).

Feyles, V.C. \& Kennedy, T.G. (1987) Inhibitory effect of the intrauterine infusion of phorbol 12-myristate 13acetate and 1-oleoyl-2-acetylglycerol on the decidual cell reaction in rats. Biol. Reprod. 37, 96-104.

Fischer, B., Winterhager, E.C. \& Busch, L.C. (1986) Transformation of endometrium and fertility in late stages of pseudopregnancy in the rabbit. $J$. Reprod. Fert. 78, 529-540.

Fortier, M.A. \& Boulanger, M. (1986) Detection and regulation of hormone sensitive adenylate cyclase in epithelial cells from rabbit uterus and oviduct. Biol. Reprod. 34, 193 (abstr).

Fortier, M., Chase, D., Korenman, S.G. \& Krall, J.F. (1983) $\quad \beta$-adrenergic catecholamine-dependent properties of rat myometrium primary cultures. $\mathrm{Am}$. J. Physiol. 245 (Cell Physiol.14), C84 C90.

Fortier, M.A., Boulanger, M., Boulet, A.P. \& Lambert, R.D. (1987) Cell-specific localization of prostaglandin $E_{2}$-sensitive adenylate cyclase in rabbit endometrium. Biol. Reprod. 36, 1025-1033.

Fortier, M.A., Guilbault, L.A. \& Grasso, F. (1988) Specific properties of epithelial and stromal cells from the endometrium of cows. J. Reprod. Fert. 83, 239-248.

Harper, M.J.K., Norris, C.J. \& Rajkumar, K. (1983) Prostaglandin release by zygotes and endometria of pregnant rabbits. Biol. Reprod. 28, 350-362.

Hearn, J.P. (1986) The embryo maternal dialogue during early pregnancy in primates. $J$. Reprod. Fert. 76, 809-819.

Johnston, M.E.A. \& Kennedy, T.G. (1984) Estrogen and uterine sensitization for the decidual cell reaction in the rat: role of prostaglandin $\mathrm{E}_{2}$ and adenosine $3,5^{\prime}-$ cyclic monophosphate. Biol. Reprod. 31, 959-966.

Kennedy, T.G. (1983) Prostaglandin $\mathrm{E}_{2}$, adenosine $3^{\prime}, 5^{\prime}$ cyclic monophosphate and changes in endometrial vascular permeability in rat uteri sensitized for the decidual cell reaction. Biol. Reprod. 29, 1069-1076.

Kennedy, T.G. (1986) Prostaglandins and uterine sensitization for the decidual cell reaction. Ann. N.Y. Acad. Sci. 476, 43-48.

Kennedy, T.G. (1987) Interactions of eicosanoids and other factors in blastocyst implantation. In Eicosanoids and Reproduction, pp. 73-88. Ed. K. Hillier. MTP Press, Lancaster.

Kennedy, T.G., Martel, D. \& Psychoyos, A. (1983) Endometrial prostaglandin $E_{2}$ binding: characterization in rats sensitized for the decidual cell reaction and changes during pseudopregnancy. Biol. Reprod. 29, 556-564.

Krall, J.F. \& Korenman, S.G. (1979) Regulation of uterine smooth muscle cell beta-adrenergic catecholamine-sensitive adenylate cyclase by $\mathrm{Mg}^{++}$ and guanylyl nucleotide. Biochem. Pharmacol. 28 , 2771-2775.

Krall, J.F., Leshon, S.C., Frolich, M. \& Korenman, S.G. (1981) Activation of uterine smooth muscle adenylate cyclase by guanyl nucleotide. $J$. biol. Chem. 256, 5436-5442.

Kuehl, F.A., Cirillo, V.J., Zanetti, M.E., Beveridge, G.C. \& Ham, E.A. (1976) The effect of estrogen upon cyclic nucleotide and prostaglandin levels in the rat uterus. Adv. Prostagl. Thrombox. Res. 1, 313-324.

Lowry, O.H., Rosebrough, N.J., Farr, A.L. \& Randall, R.J. (1951) Protein measurement with the folin phenol reagent. J. biol. Chem. 193, 265-275.

Moulton, B.C. \& Koenig, B.B. (1986) Biochemical responses of the luminal epithelium and uterine sensitization. Ann. N.Y. Acad. Sci. 476, 95-109.

Psychoyos, A. (1986) Uterine receptivity for nidation. Ann. N.Y. Acad. Sci. 476, 36-42.

Psychoyos, A. \& Casimiri, V. (1980) Factors involved in uterine receptivity and refractoriness. Progr. Reprod. Biol. 7, 143-157.

Rankin, J.C., Ledford, B.E. \& Baggett, B. (1977) Early involvement of cyclic nucleotides in the artificially stimulated decidual cell reaction in the mouse uterus. Biol. Reprod. 17, 549-554.

Rodbard, D. (1974) Apparent positive cooperative effect in cyclic AMP and corticosterone production by related adrenal cells in response to ACTH analogs. Endocrinology 94, 1427-1437.

Tolszczuk, M., Williams, L., Schimschowitsch, S. \& Pelletier, G. (1985) Localization radioautographique des récepteurs $\beta$-adrénergiques dans les trompes utérines et l'utérus chez le rat. Union Méd. Canada 114, 703, Abstr. 
Villar-Rojas, C., Castro-Osuma, G. \& Hicks, J.J. (1982) Cyclic AMP and cyclic GMP in the implantation sites of the rats. Int. J. Fertil. 27, 56-59.

Wilmut, I., Sales, D.I. \& Ashworth, C.J. (1986) Maternal and embryonic factors associated with prenatal loss in mammals. J. Reprod. Fert. 76, 851-864.
Yang, J., Guxman, R., Richards, J., Imagawa, W., McCormick, K. \& Nandi, S. (1980) Growth factorand cyclic nucleotide-induced proliferation of normal and malignant mammary epithelial cells. Endocrinology 107, 35-41.

Received 10 May 1988 